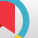

\title{
Green Synthesis of Gold Nanoparticles Using Barberry and Saffron
} Extracts

\author{
Zahra Abootorabi, ${ }^{1}$ Maliheh Poorgholami, ${ }^{2}$ Mohamad Yahya Hanafi-Bojd, ${ }^{2}$ and Reyhane Hoshyar ${ }^{2,}$ \\ ${ }^{1}$ Student Research Committee, Birjand University of Medical Sciences, Birjand, IR Iran \\ ${ }^{2}$ Cellular and Molecular Research Center, Birjand University of Medical Sciences, Birjand, IR Iran \\ "Corresponding author: Reyhane Hoshyar, Cellular and Molecular Research Center, Birjand University of Medical Sciences, Birjand, IR Iran. Tel: +98-9382588299, E-mail: \\ reyhaneh.houshyar@gmail.com
}

Received 2016 August 06; Revised 2016 September 13; Accepted 2016 October 12.

\begin{abstract}
Recently, synthesis of gold nanoparticles (AuNPs) is the subject of a lot of studies due to various applications in medicine, agriculture, and industry. The development of non-toxic and safe methods such as green chemistry to produce AuNPs is obviously recommended. In the current study, 2 antioxidant rich herbs of barberry and saffron stigma were applied as reducing agents for the 1-pot synthesis of size-controlled AuNPs. These AuNPs were characterized through ultraviolet-visible spectrophotometry (UV-vis), transmission electron microscopy (TEM), and X-ray diffraction (XRD) techniques. Optimal temperature and $\mathrm{pH}$ for the biosynthesis of AuNPs conjugated with herbs were $50^{\circ} \mathrm{C}$ and 7.5, respectively. XRD and TEM results authorized AuNPs production in $5-15 \mathrm{~nm}$ for barberry and 5 - $10 \mathrm{~nm}$ for saffron and confirmed the stability, sphericity, and uniformity for both the nanoparticles.
\end{abstract}

Keywords: AuNPs, Barberry, Saffron, Antioxidan

\section{Background}

Berberis vulgaris (barberry) and Crocus sativus (saffron) are well known plants with traditional and modern medical applications. Their phytochemical analysis indicated the presence of many effective metabolites with antioxidant, anti-inflammatory, anticancer, and immunosuppressive activities (1-3). In the current study, high antioxidant properties of barberry and saffron were employed to reduce gold ions for green synthesis of AuNPs. Nanoparticles are used in many fields such as pharmacology, medicine, agriculture, and electronic engineering (46). Among them, AuNPs are applied in important biological mechanisms including drug delivery, cancer diagnosis, and treatment due to their unique chemical and physical features (7). Due to the increasing need to develop nontoxic and eco-friendly methods, employment of renewable environmental resources is recently considered.

Formerly, there were a lot of reports on synthesis of metal nanoparticles using different biomolecules such as filamentous cyanobacteria (8), bacteria, microbes $(9,10)$, and plants (11). Among them, plants are more suitable and compatible due to optimal environmental preservation, fast, simple production and high stability of particles (12, 13). In addition, these organic nanoparticles can be used for molecular medicine as well as modern care in future.
The current study aimed at optimization a green chemical method to synthetize AuNPs in short reaction time.

\section{Methods}

Different concentrations of gold ions $\left(\mathrm{HAuCl}_{4}, 0-5\right.$ $\mathrm{mM}$ ) and herbal extractions as reducing agents (300 to $700 \mathrm{mM}$ ) were used at various times (from 2 hours to 8 weeks) and temperatures $\left(25-75^{\circ} \mathrm{C}\right)$ to investigate the effects of different conditions on size and amount of generated AuNPs. The $\mathrm{pH}$ of solution in all experiments was fixed at 7.5. To separate AuNPs, final solutions were centrifuged 3 times for 15 minutes at 10,000 rpm. The optical absorption spectra of both solutions were determined by ultravioletvisible (UV-Vis) spectrophotometry (2030 CECIL Company, UK) in the range of 520 to 550 nanometers.

The crystalline structures and corresponding morphology of the prospered AuNPs were assayed by X-ray diffraction (XRD) (Philips, X'pert-MPD system using $\mathrm{CuK} \alpha$ ) and transmission electron microscopy (TEM) (TEMZIESS, TEM PHILPS) techniques, respectively. The line broadening was based on the instrument computed from the Warren method (14). 


\section{Results}

The AuNPs were produced by the mixture of $4 \mathrm{~mL}$ of $\mathrm{HAuCl}_{4}(1 \mathrm{mM})$ and $6 \mathrm{~mL}$ of herbal extractions $(2 \mathrm{mM})$ after 24 hours at $50^{\circ} \mathrm{C}$. The reduction of gold ions in AuNPs changed the color of solution from colorless to light and dark purple with barberry and saffron, respectively. The enhancement of intensity of spectrums especially after 24 hours could be due to increasing the number of AuNPs (Figure 1). It is observed that the surface plasmon resonance (SPR) band occurs at $520 \mathrm{~nm}$. Absorptions of AuNPs conjugated with both herbs were similar (Figure 1).

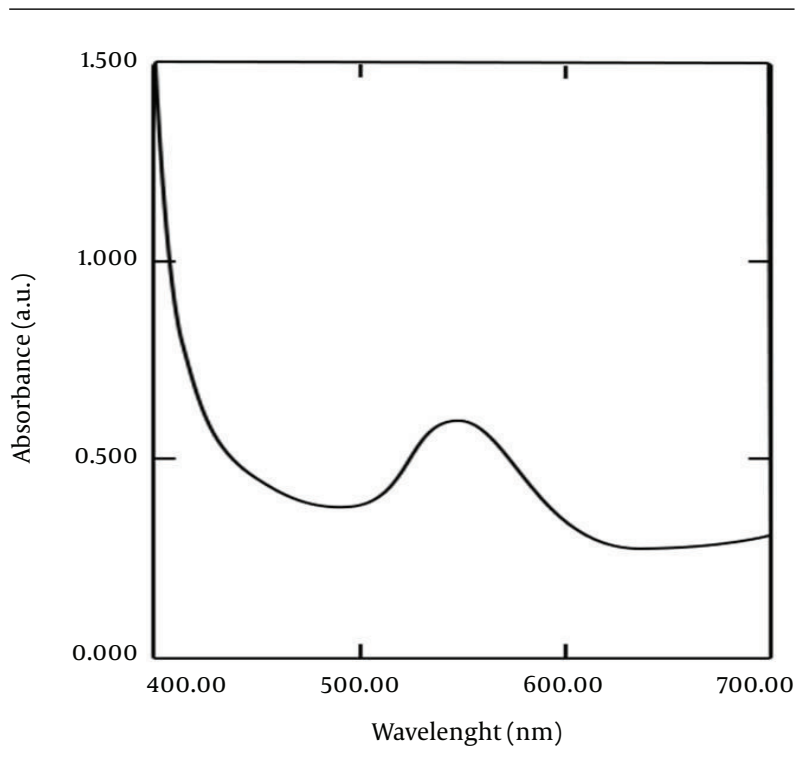

Figure 1. UV-Vis Spectrum of AuNPs after 24 Hours at $50^{\circ} \mathrm{C}$ and $\mathrm{pH} 7.5$

XRD patterns of AuNPs conjugated with both herbs are shown in Figure 2. Peak broadening of AuNPs can be related to a decrease in particle size. According to the Scherer equation, the average of crystallite size was calculated by the width of the X-ray peak. The diameter average of AuNPs obtained from barberry and saffron were around 10 and 7 $\mathrm{nm}$, respectively (Figure 2). TEM images of nanoparticles indicated nearly spherical nanoparticles with particle size about 5-15 nm for barberry and 5-10 nm for saffron, which were in agreement with XRD results (Figure 3 ).

\section{Discussion}

The biosynthesis of AuNPs using barberry and saffron was reported in the current study for the first time. Parameters affecting size and shape of these AuNPs were studied and optimized.

Recently, green synthesis of AuNPs applying various plant extractions is investigated. According to the size of
A

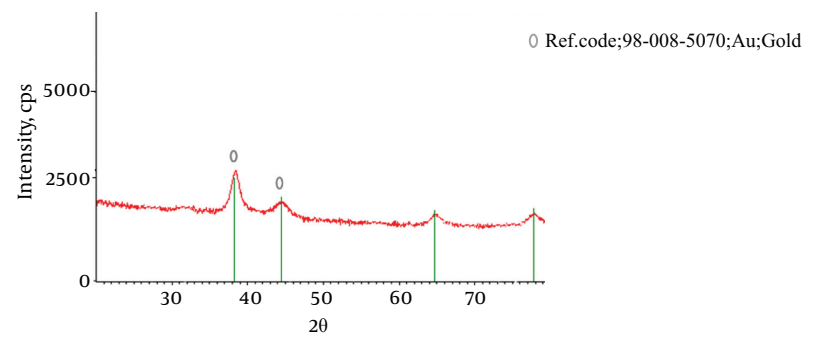

B

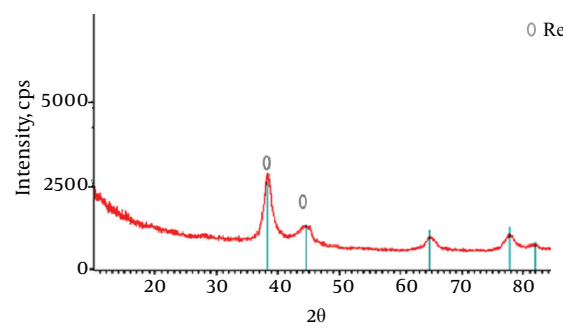

Figure 2. XRD Patterns of AuNPs at $50^{\circ} \mathrm{C}$ and $\mathrm{pH} 7.5$ for A, Barberry; B, and Saffron

these prepared nanoparticles, they could be divided into 3 main groups. In the first group, the synthesized AuNPs were $100-150 \mathrm{~nm}$. For example in a study, these particles were $150 \mathrm{~nm}$ in spherical shape with the Mentha piperita (Lamiaceae) plant extract(6). In the second group, the prepared AuNPs were predominantly nano-triangle in shape, with diameters ranging from 50 to $100 \mathrm{~nm}$. Several researches worked on biosynthesis of AuNPs with monodisperse and roughly spherical shape using olive leaf and Azadirachta indica extracts as the reducing agents (5, 15). In the third group, TEM analysis of the AuNPs indicated that they ranged in size $<50 \mathrm{~nm}$. Different studies reported green synthesis of AuNPs with triangular and spherical shape with well-defined dimensions of average size of 2 - $50 \mathrm{~nm}$ using herbal extracts such as Terminalia catappa (almond) leaf as the reducing and stabilizing agents (4). As a result, the synthesized AuNPs in the current study were placed in the third group.

In conclusion, the current study data clearly indicated that the formed AuNPs by both herbs had almost a uniform size and morphology with rough spherical shape. These prepared AuNPs were predominantly mono disperse with a diameter of $5-10 \mathrm{~nm}$ and $5-15 \mathrm{~nm}$ for saffron and barberry, respectively. Almost 24 hours of reaction time is required for conversion of almost all gold ions to AuNPs at the temperature of $50^{\circ} \mathrm{C}$ and $\mathrm{pH}$ 7.5. This simple, low cost, stable, and safe method to extend AuNPs can be strongly useful in environmental and biotechnological processes. These safe AuNPs could also be applied to pharmacology 

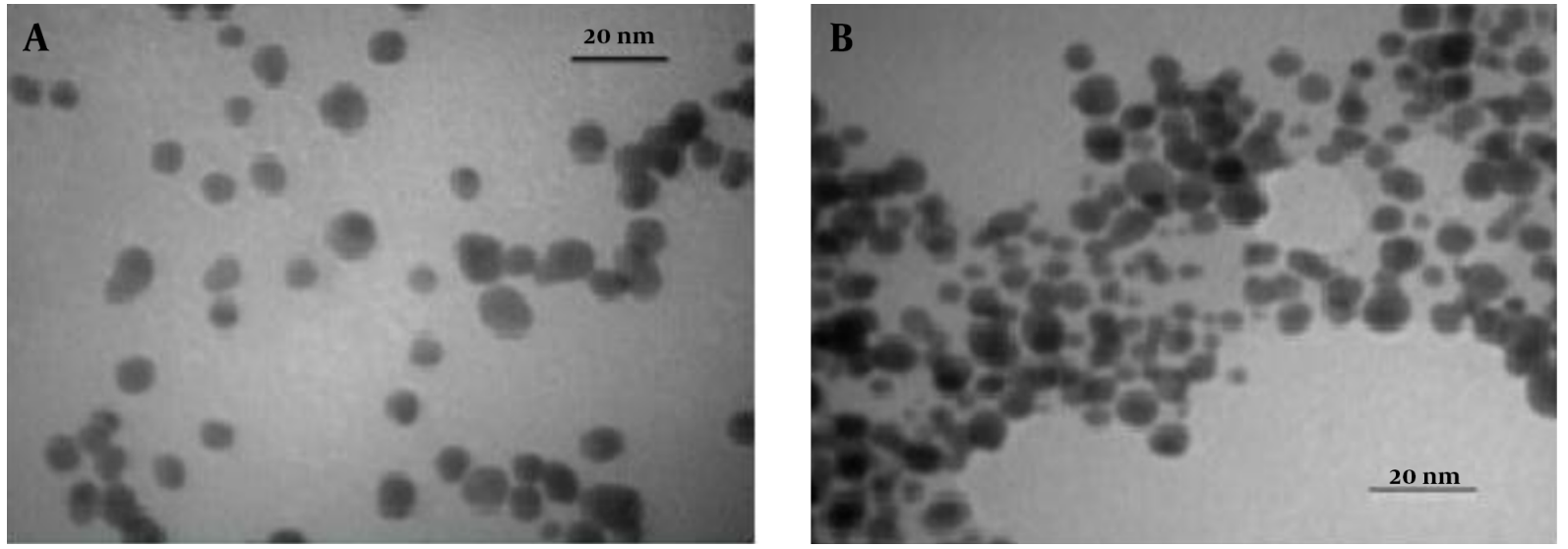

Figure 3. Typical TEM Image of AuNPs at $50^{\circ} \mathrm{C}$ and $\mathrm{pH} 7.5$ for A, Barberry; and B, Saffron

and modern therapy approaches.

\section{Acknowledgments}

The current study was granted (No. 69/93) by the vice chancellor of research, Birjand University of Medical Sciences, Iran.

\section{References}

1. Mahdavi N, Joukar S, Najafipour H, Asadi-Shekaari M. The promising effect of barberry (Zereshk) extract against experimental pulmonary microvascular remodeling and hypertension: A comparison with sildenafil. Pharm Biol. 2016;54(3):509-15. doi: 10.3109/13880209.2015.1050676. [PubMed: 26023989].

2. Hoshyar R, Bathaie SZ, Kyani A, Mousavi MF. Is there any interaction between telomeric DNA structures, G-quadruplex and I-motif, with saffron active metabolites? Nucleosides Nucleotides Nucleic Acids. 2012;31(11):801-12. doi: 10.1080/15257770.2012.730164. [PubMed: 23145950].

3. Hoshyar R, Bathaie SZ, Sadeghizadeh M. Crocin triggers the apoptosis through increasing the Bax/Bcl-2 ratio and caspase activation in human gastric adenocarcinoma, AGS, cells. DNA Cell Biol. 2013;32(2):50-7. doi: 10.1089/dna.2012.1866. [PubMed: 23347444].

4. Ankamwar B. Biosynthesis of gold nanoparticles (Green-gold) using leaf extract of Terminalia catappa. E-J Chem. 2010;7(4):1334-9. doi: $10.1155 / 2010 / 745120$.

5. Konwar Boruah S, Kumar Boruah P, Sarma P, Medhi C, Kumar Medhi O. Green synthesis of gold nanoparticles using camelliasinensis and kinetics of the reaction. Adv Mater Letters. 2012;3(6):481-6. doi: 10.5185/amlett.2012.icnano.103.

6. MubarakAli D, Thajuddin N, Jeganathan K, Gunasekaran M. Plant extract mediated synthesis of silver and gold nanoparticles and its antibacterial activity against clinically isolated pathogens. Colloids Surf
B Biointerfaces. 2011;85(2):360-5. doi: 10.1016/j.colsurfb.2011.03.009. [PubMed: 21466948].

7. Hoshyar R, Khayati GR, Poorgholami M, Kaykhaii M. A novel green one-step synthesis of gold nanoparticles using crocin and their anti-cancer activities. J Photochem Photobiol B. 2016;159:237-42. doi: 10.1016/j.jphotobiol.2016.03.056. [PubMed: 27085640].

8. Lengke MF, Fleet ME, Southam G. Morphology of gold nanoparticles synthesized by filamentous cyanobacteria from gold(I)-thiosulfate and gold(III)-chloride complexes. Langmuir. 2006;22(6):2780-7. doi: 10.1021/la052652c. [PubMed: 16519482].

9. Saifuddin N, Wong CW, Yasumira AA. Rapid biosynthesis of silver nanoparticles using culture supernatant of bacteria with microwave irradiation. E-J Chem. 2009;6(1):61-70. doi: 10.1155/2009/734264.

10. Narayanan KB, Sakthivel N. Biological synthesis of metal nanoparticles by microbes. Adv Colloid Interface Sci. 2010;156(1-2):1-13. doi: 10.1016/j.cis.2010.02.001.

11. Chandran SP, Chaudhary M, Pasricha R, Ahmad A, Sastry M. Synthesis of gold nanotriangles and silver nanoparticles using Aloe vera plant extract. Biotechnol Prog. 2006;22(2):577-83. doi: 10.1021/bp0501423. [PubMed: 16599579].

12. Moulton MC, Braydich-Stolle LK, Nadagouda MN, Kunzelman S, Hussain SM, Varma RS. Synthesis, characterization and biocompatibility of "green" synthesized silver nanoparticles using tea polyphenols. Nanoscale. 2010;2(5):763-70. doi:10.1039/c0nr00046a. [PubMed: 20648322].

13. Nadagouda MN, Varma RS. Green synthesis of silver and palladium nanoparticles at room temperature using coffee and tea extract. Green Chem. 2008;10(8):859-62. doi: 10.1039/b804703k.

14. Bolhasani A, Bathaie SZ, Yavari I, Moosavi Movahedi AA, Ghaffari M. Separation and purification of some components of Iranian saffron. Asian J Chem. 2005;17(2):727-9.

15. Khalil MM, Ismail EH, El Magdoub F. Biosynthesis of Au nanoparticles using olive leaf extract. Arab J Chem. 2012;5(4):431-7. doi: 10.1016/j.arabjc.2010.11.011. 